\title{
Incidence of penicillinase producing Neisseria gonorrhoeae (PPNG) strains and susceptibility of gonococcal isolates to antibiotics in Benin City, Nigeria
}

\author{
E E OBASEIKI-EBOR, * S M OYAIDE, † AND E E OKPERE \\ From the *Department of Pharmaceutical Microbiology, Faculty of Pharmacy, and the + Department of \\ Medical Microbiology, University of Benin, and the £Department of Obstetrics and Gynaecology, \\ University of Benin Teaching Hospital, Benin City, Nigeria
}

SUMMARY Of 53 strains of Neisseria gonorrhoeae isolated in Benin City, Nigeria, in February 1983 to October $1984,46(87 \%)$ produced penicillinase. The minimum inhibitory concentrations (MICs) of penicillin $G$ and ampicillin for these isolates were between $1 \mathrm{mg} / 1$ and $50 \mathrm{mg} / \mathrm{l}$. About $48 \%(22 / 46)$ of the penicillinase producing strains were also resistant to streptomycin, cotrimoxazole, and ampicillin and cloxacillin. All 53 isolates were sensitive to tetracycline, erythromycin, amoxycillin and clavulanic acid, nalidixic acid, spectinomycin, and the penicillinase stable cephalosporins. The high incidence of resistance may have been the result of indiscriminate and unsupervised use of antibiotics before patients presented for proper treatment in clinics and hospitals.

\section{Introduction}

$\beta$ Lactam antibiotics have been the most commonly used drugs for treating acute uncomplicated gonococcal infections. It was perhaps to be expected that the emergence of penicillinase producing strains of Neisseria gonorrhoeae (PPNG) would in a matter of time threaten the successful application of penicillin $G$ and ampicillin in treating these infections.

PPNG strains were first recognised in the United States $^{1}$ and the United Kingdom ${ }^{23}$ in 1976. Although by 1977 the presence of PPNG strains had not been noticed in Nigeria, ${ }^{4}$ they were isolated at Ibadan in early 1979,5 with a prevalence of about $12 \cdot 5 \%$ compared with that of $36 \%$ in Ghana. The prevalence of PPNG strains in Nigeria had risen to $20 \%$ by late 1979, 22\% in 1980 (Osoba AO and Ogunbanjo, unpublished observation) and 50\% in 1981 (Osoba AO et al, unpublished observation). PPNG strains were subsequently found in and around Enugu, where their incidence was about $73 \%$ in $1981 ;^{6}$ while

Address for reprints: Dr E E Obaseiki-Ebor, Department of Pharmaceutical Microbiology, Faculty of Pharmacy, University of Benin, Benin City, Nigeria

Accepted for publication 28 February 1985 in the northern states of Nigeria "diminished sensitivity" of $N$ gonorrhoeae to penicillin, tetracycline, streptomycin, and chloramphenicol had been reported, ${ }^{7}$ although PPNG strains were not specifically mentioned.

Nigeria is the largest country in West Africa, with an area of about 360000 square miles lying between latitudes $4^{\circ}$ and $14^{\circ} \mathrm{N}$ and extending north from the coast for about 800 miles. Its population is over 100 million. In the central southern area of Nigeria, such as the densely populated state capital of Benin City, the prevalence and sensitivity pattern of $N$ gonorrhoeae isolates to antibiotics have not been assessed. Benin City is, however, at risk of subregional dissemination of PPNG strains because many travellers from the eastern, northern, and western regions of Nigeria visit the city. Also travellers by sea from across the Atlantic Ocean to the sea ports of Warri, Sapele, and Forcados eventually come to Benin City because of its geographical situation and diverse institutions.

This paper presents the incidence during a 20 month period of $N$ gonorrhoeae isolates from men in Benin City, and reports on their susceptibility to the $\beta$ lactam and other antibiotics. 
Patients and methods

In February 1983 to October 1984 we examined strains of $N$ gonorrhoeae from 101 men presenting with acute gonoccal urethritis. Information regarding past medication by the patients could not be obtained. Generally, however, self medication with antibiotics is common.

Specimens were obtained from two main sources: private laboratories (Fenlab, Owobu, and Opri) and from hospitals (the general practice clinic and staff health centre, department of medical microbiology, University of Benin Teaching Hospital, and the Nigeria air force clinic, Benin City). Specimens from the private laboratories were taken by using cotton wool swabs to collect the discharge from the anterior urethra, and were stored in Stuart's transport medium awaiting transportation to the research laboratory for cultivation. The urethal discharges from the hospital patients were collected with nichrome wire loops. All specimens were inoculated on to prewarmed (at $37^{\circ} \mathrm{C}$ ) plates of Thayer-Martin medium (Oxoid) consisting of GC agar base (Oxoid CM 367) and non-selective gonococcal agar (GCA) supplemented with haemoglobin and vancomycin, nystatin, colistin, and trimethoprim (VNCT). The plates were incubated at $37^{\circ} \mathrm{C}$ in candle extinction jars for 24 to $\mathbf{4 8}$ hours.

Typical colonies were selected and Gram stained. All Gram negative diplococci were further identified after subculture on GCA agar by the oxidase test and sugar fermentation reactions using standard methods. ${ }^{8}$ Control strains consisted of non-PPNG strain 9, $N$ meningitidis B-2 (both provided by $\mathrm{Dr} H$ Young, Department of Bacteriology, Royal Infirmary, Edinburgh), and Oxford Staphylococcus aureus (NCTC 6971).

\section{DISC SENSITIVITY TESTING}

GCA plates (Oxoid) were inoculated with colonies of the isolates in a manner similar to the Kirby-Bauer method. ${ }^{9}$ Multidisc (code 1789E, Oxoid) was used and single discs containing cefotaxime $30 \mu \mathrm{g}$, ceftriaxone $30 \mu \mathrm{g}$, or amoxycillin and clavulanic acid (Augmentin), $25 \mu \mathrm{g}$, were aseptically placed on the plates. Results were read after incubation for 18 to 24 hours as above. (An isolate was said to be sensitive if the zone of inhibition round the disc was greater or equal to that of the control. A resistant organism was one that had a zone of less than $2 \mathrm{~mm}$ round the disc.)

\section{ASSESSMENT OF MINIMUM INHIBITORY}

CONCENTRATIONS (MICs)

The MICs of the antibiotics were established by agar plate dilution using the modified method of Osoba et $a l .{ }^{4}$ Colonies of the test strain were picked from a 48 hour culture on GC agar and emulsified in sterile broth. The concentration was adjusted visually to correspond to $0.05 \mathrm{McF}$ arland standard barium sulphate. The plates were then inoculated with loops from the bacterial suspensions containing about $10^{4}$ to $10^{5}$ colony forming units $(\mathrm{cfu}) / \mathrm{ml}$, and were incubated at $37^{\circ} \mathrm{C}$ for 18 to 24 hours. The lowest concentration of antibiotic to inhibit growth was regarded as the MIC for that strain. A control plate without an antibiotic, and plates containing antibiotics against the reference strains, were included.

\section{INHIBITION AND SENSITIVITY OF CONTROL STRAINS}

The MICs of some antibiotics against the control strains and their disc sensitivity were as follows: $N$ gonorrhoeae and $N$ meningitidis B-2 were inhibited by $0.05 \mathrm{mg} / 1$ ampicillin and $0.5 \mathrm{mg} / 1$ tetracycline and were sensitive to 1.5 IU penicillin $G$ and $2 \mu \mathrm{g}$ ampicillin discs; Oxford Staph aureus was inhibited by $0.5 \mathrm{mg} / \mathrm{l}$ ampicillin and was sensitive to $1.5 \mathrm{IU}$ penicillin $G$ and $2 \mu \mathrm{g}$ ampicillin discs.

\section{PRODUCTION OF PENICILLINASE}

Oxford Staph aureus test strain was streaked on GCA plates using the Kirby-Bauer method as described by Hodge et al. ${ }^{10} \mathrm{~A} 10 \mathrm{IU}$ or $2 \mathrm{IU}$ penicillin G disc was placed at the centre of the plate and a heavy inoculum of the test strain was streaked radially outwards from the disc. Production of penicillinase was indicated by the distortion of the zone of inhibition to penicillin. This method favourably matched the development of a pinkish coloration with a nitrocefin disc, using the method of O'Callaghan et al, " within one hour on plates streaked with PPNG strains. Control strains were included in both tests.

\section{Results}

Fifty three isolates of $N$ gonorrhoeae were obtained from the 101 men screened during the 20 month study period.

\section{DISC SENSITIVITY}

In the disc diffusion sensitivity tests, all 53 strains $(100 \%)$ were sensitive to tetracycline, erythromycin, nalidixic acid, amoxycillin and clavulanic acid, cefuroxime, cefotaxime, and ceftriaxone. Seven $(13 \%)$ were sensitive to penicillin $G$, five $(9 \%)$ to streptomycin, seven $(13 \%)$ to ampicillin, $21(40 \%)$ to cloxacillin, and $21(40 \%)$ to cotrimoxazole.

MINIMUM INHIBITORY CONCENTRATIONS (MICS) The table shows the cumulative percentages of 40 
Incidence of PPNG strains and susceptibility to antibiotics in Benin City, Nigeria.

TABLE Cumulative percentages of 40 Neisseria gonorrhoeae isolates inhibited by various antibiotics

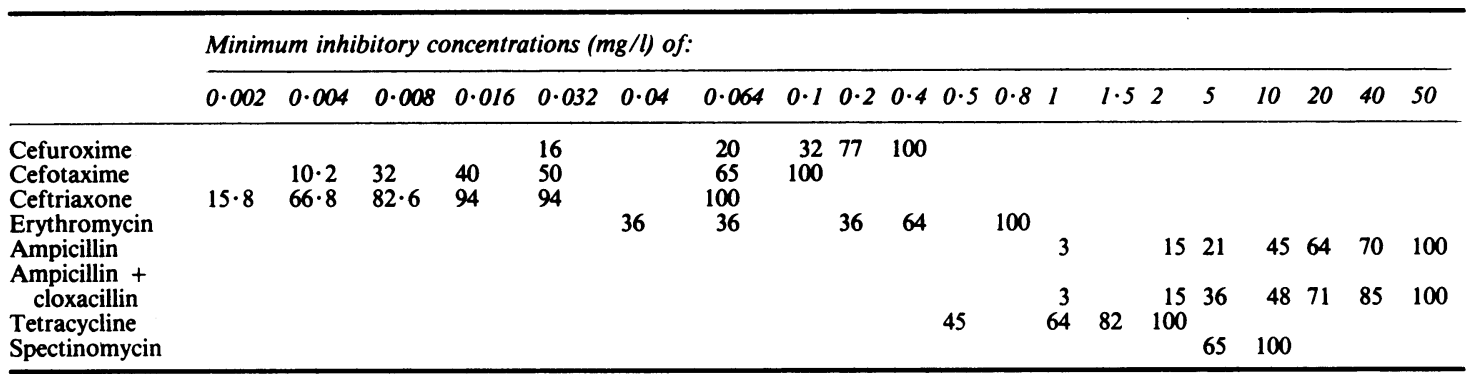

isolates inhibited by various antibiotics. The other 13 isolates were lost before the MICs of antibiotic against them could be established. All the isolates were sensitive to ceftriaxone, cefotaxime, cefuroxime, erythromycin, spectinomycin, and tetracycline similarly to the results seen in the disc sensitivity tests. All the isolates tested were resistant (not inhibited by $\geqslant 0.1 \mathrm{mg} / \mathrm{l}$ ) to ampicillin. The difference between the susceptibility of the test isolates to ampicillin and cloxacillin (Ampiclox) compared with ampicillin was not significant. The MICs of ampicillin and Ampiclox were between 1 $\mathrm{mg} / \mathrm{l}$ and $50 \mathrm{mg} / \mathrm{l}$.

\section{PRODUCTION OF PENICILLINASE}

About $87 \%(46 / 53)$ of the isolates produced penicillinase. Almost all the strains resistant to $1.5 \mu \mathrm{g}$ penicillin $G$ and $2 \mu \mathrm{g}$ ampicillin discs were found to produce penicillinase. Only one isolate resistant to penicillin $G$ and ampicillin did not produce penicillinase. About 74\% (34/46) of the PPNG strains had similar patterns of susceptibility and resistance to penicillin G, ampicillin, ampicillin and cloxacillin, streptomycin and co-trimoxazole.

\section{Discussion}

The relatively small number (53) of isolates positively identified as $N$ gonorrhoeae from 101 men with gonoccal urethritis does not of course reflect the true prevalence of gonococcal infection, as most patients prefer self medication with antibiotics. Such patients, however, present themselves to clinics after antibiotic self medication has failed. One of the effects of the indiscriminate use of antibiotics in these circumstances is the suppression of infection without its eradication. ${ }^{12}$ Another problem is the evolution of strains resistant to multiple antibiotics, such as were obtained in these isolates. In Kampala such multiple resistance, in which resistance to penicillin and streptomycin were often linked, was reported in strains of $N$ gonorrhoeae. ${ }^{13}$

The incidence of PPNG strains as a percentage of all strains of $N$ gonorrhoeae has been reported as
$10 \%$ in 1981 in the Netherlands, ${ }^{14} 48 \%$ in Korea in $1981,{ }^{15} 19 \%$ in Singapore in $1979,{ }^{16}$ and $12 \%$ in Saudi Arabia between April 1979 and August 1980. ${ }^{17}$ The appreciably higher percentage of PPNG strains found during 20 months in this study represents the highest incidence in the world. This high incidence could obviously jeopardise the use of ampicillin as a first line treatment of infections with $\mathrm{N}$ gonorrhoeae in our area. The $50 \%$ positive identification of $N$ gonorrhoeae in symptomatic men with urethral discharge clearly indicates that an undefined but appreciable proportion of these patients possibly had non-gonococcal urethritis (NGU). As tetracycline is highly effective against chlamydiae, this drug could be the drug of first choice in managing patients presenting with urethral discharge in Nigeria. It was remarkable that all the isolates were highly sensitive to tetracycline at a MIC of $\leqslant 2 \mathrm{mg} / 1$ and to erythromycin at $0.8 \mathrm{mg} / \mathrm{l}$. The susceptibility of $N$ gonorrhoeae to tetracycline in this study compares favourably with the results of MIC $\leqslant 2 \mathrm{mg} / \mathrm{l}$ obtained in Ibadan (Osoba AO et al, unpublished observation) and in other places such as the United States and the Netherlands. ${ }^{14}$ Susceptibility of the isolates in this study to clavulanic acid indicated that the prevalent types of penicillinase produced by all the test isolates could be among the penicillinases of Richmond types II, III, IV, and V. ${ }^{18}$ The high incidence of PPNG strains in this study contradicts the general opinion in other parts of the world that most of the penicillin resistant gonococcal strains do not produce penicillinase and gradually become intrinsically resistant or have diminished sensitivity. ${ }^{419}$

In conclusion, it is important to survey the susceptibility of gonococci to antibiotics regularly. In Nigeria it would be more cost effective to start treatment with the relatively cheap and easily available antibiotics, such as tetracycline and erythromycin, before considering the newer and more expensive generations of cephalosporin antibiotics.

We thank our professional colleagues for their interest and efforts in isolating strains of $N$ gonorrhoeae. E E O-E was in receipt of University of Benin staff research grant $\mathrm{C} / 300$. 


\section{References}

1. Ashford WA, Golash RG, Hemming VG. Penicillinaseproducing Neisseria gonorrhoeae. Lancet 1976; ii:657-8.

2. Percival A, Rowland J, Corkill JE, et al. Penicillinaseproducing gonococci in Liverpool. Lancet 1976; ii: 1379-82.

3. Phillips I. $\beta$-lactamase-producing, penicillin-resistant gonococcus. Lancet 1976; ii:656-7.

4. Osoba AO, Montefiore DG, Sogbetun AO, Alausa KO, Anong CN. Sensitivity pattern of Neisseria gonorrhoeae to penicillin and screening for beta-lactamase production in Ibadan, Nigeria. British Journal of Venereal Diseases 1977;53:3047.

5. Osoba AO, Afoakwa SN, Twun Danso R, Ochei J. Penicillinase producing Neisseria gonorrhoeae in West Africa. WHO/VDT/ RES/GON/81 1981;132.

6. Egere JU, Mbonu OO, Okaro J, Anozie SO, Balakrishnam P. Cefotaxime in the treatment of gonococcal urethritis in Nigeria. Clinical Trials Journal 1982;19:162-9.

7. Jain PS. Treatment of gonorrhoeae with spectinomycin hydrochloride (Togamycin) in university students. Niger Med J 1975;5:254.

8. Cowan ST, Steel KJ. Manual for the identification of medical bacteria. 2nd ed. London: Cambridge University Press, 1974.

9. Bauer AW, Kirby WMM, Sherris JC, Turck M. Antibiotic susceptibility testing by a standardised single disc method. $A m$ $J$ Clin Pathol 1966; 45:493-6.

10. Hodge W, Ciak J, Tramont EC. Simple method for detection of penicillinase-producing Neisseria gonorrhoeae. J Clin Microbiol 1978; 7:102-3.
11. O'Callaghan $\mathbf{C H}$, Morris A, Kieby SM, Shingler AH. Novel method for detection of beta-lactamases by using a chromogenic cephalosporin substrate. Antimicrob Agents Chemother 1972;1:283-8.

12. Fakunle YM, Watkins B. Influence of self-medication on prevalence and antibiotic sensitivity of $\mathbf{N}$ gonorrhoeae in Zaria (Nigeria). East Afr Med J 1976;53:693-6.

13. Phillips I, Fernandes R, Pirani AA, Wagaire D. Antibiotic sensitivity of gonococci in Kampala. East Afr Med J 1969; 46:38-45.

14. Van Klingeren B, Van Wijngaarden LJ, Dessens-Kroon M, Van Embden JDA. Penicillinase-producing gonococci in the Netherlands in 1981. J Antimicrob Chemother 1983;11:15-20.

15. Piziak MV, Woodbury C, Berliner D, et al. Resistance trends in $N$ gonorrhoea in the Republic of Korea. Antimicrob Agents Chemother 1984;25:7-9.

16. Rajan VS, Thirumoorthy T, Tan NJ. Epidemiology of penicillinase-producing Neisseria gonorrhoeae in Singapore. British Journal of Venereal Diseases 1981;57:158-61.

17. Chowdhurry MNH, Pareek SS, Mahgoub E. Penicillinaseproducing Neisseria gonorrhoeae in Ryadh, Saudi Arabia. British Journal of Venereal Diseases 1981;57:256-8.

18. Neu HC, Fu KP. Clavulanic acid, a novel inhibitor of betalactamases. Antimicrob Agents Chemother 1978;14:650-5.

19. Dougherty TJ, Kollier AE, Tomesz A, Penicillin-binding proteins of penicillin-susceptible and intrinsically resistant Neisseria gonorrhoeae. Antimicrob Agents Chemother 1980; 18:730-7. 